\title{
Human Monoclonal Antibody Combination against SARS Coronavirus: Synergy and Coverage of Escape Mutants
}

\author{
Jan ter Meulen ${ }^{1 \odot *}$, Edward N. van den Brink ${ }^{1 \odot}$, Leo L. M. Poon ${ }^{2}$, Wilfred E. Marissen ${ }^{1}$, Cynthia S. W. Leung ${ }^{2}$, \\ Freek Cox ${ }^{1}$, Chung Y. Cheung ${ }^{2}$, Arjen Q. Bakker ${ }^{1}$, Johannes A. Bogaards ${ }^{1}$, Els van Deventer ${ }^{1}$, Wolfgang Preiser ${ }^{3}$, \\ Hans Wilhelm Doerr ${ }^{3}$, Vincent T. Chow ${ }^{4}$, John de Kruif ${ }^{1}$, Joseph S. M. Peiris ${ }^{2}$, Jaap Goudsmit ${ }^{1}$ \\ 1 Crucell Holland B.V., Leiden, Netherlands, 2 Department of Microbiology, The University of Hong Kong, Queen Mary Hospital, Hong Kong Special Administrative Region of \\ the People's Republic of China, 3 Institute for Medical Virology, Johann Wolfgang Goethe University, Frankfurt am Main, Germany, 4 Department of Microbiology, Yong Loo \\ Lin School Faculty of Medicine, National University of Singapore, Singapore
}

Funding: This work was in part supported by EU STREP grant SP22 CT2004-511064, SenterNovem grant TSGE2006 and grant Al95357 from the National Institute of Allergy and Infectious Disease. The funders had no role in study design, data collection and analysis, decision to publish, or preparation of the manuscript.

Competing Interests: Part of the direct costs (labor, cell culture material) of the SARS-CoV neutralization experiments performed with the monoclonal antibodies at the Universities of reimbursed by Crucell Holland reimbursed by Crucell Holland BV. Crucell was involved in the design the analysis of the data, and the publication decision. However, Crucell was at no time involved in performing experiments with live virus. JtM, ENvdB, WEM, FC, $A Q B$, $\mathrm{JAB}, \mathrm{EvD}$, JdK, and JG are employees of Crucell Holland BV.

Academic Editor: Dennis R. Burton, Scripps Research Institute, United

States of America

Citation: ter Meulen J, van den Brink EN, Poon LLM, Marissen WE, Leung CSW, et al. (2006) Human monoclonal antibody combination against SARS coronavirus: Synergy and coverage of escape mutants. PLoS Med 3(7): e237. DOI: 10.1371/ journal.pmed.0030237

Received: September 7, 2005

Accepted: April 3

Published: July 4, 2006

DOI:

10.1371/journal.pmed.0030237

Copyright: (c) 2006 ter Meulen et al. This is an open-access article distributed under the terms of the Creative Commons Attribution License, which permits unrestricted use, distribution, and reproduction in any medium, provided the original author and source are credited.

Abbreviations: $A D E$, antibodydependent enhancement; $\mathrm{Cl}$, combination index; $\mathrm{DRI}$, dose reduction index; mAb, monoclonal antibody; ORF, open reading frame; $\mathrm{RBD}$, receptor-binding domain; $\mathrm{S}$, spike; SARS, severe acute respiratory syndrome; SARS-CoV, SARS coronavirus; scFv, single-chain variable antibody fragment

* To whom correspondence should be addressed. E-mail: j.termeulen@ crucell.com

๑ These authors contributed equally to this work.

\section{A B S T R A C T}

\section{Background}

Experimental animal data show that protection against severe acute respiratory syndrome coronavirus (SARS-CoV) infection with human monoclonal antibodies (mAbs) is feasible. For an effective immune prophylaxis in humans, broad coverage of different strains of SARS-CoV and control of potential neutralization escape variants will be required. Combinations of virusneutralizing, noncompeting mAbs may have these properties.

\section{Methods and Findings}

Human mAb CR3014 has been shown to completely prevent lung pathology and abolish pharyngeal shedding of SARS-CoV in infected ferrets. We generated in vitro SARS-CoV variants escaping neutralization by CR3014, which all had a single P462L mutation in the glycoprotein spike (S) of the escape virus. In vitro experiments confirmed that binding of CR3014 to a recombinant $S$ fragment (amino acid residues 318-510) harboring this mutation was abolished. We therefore screened an antibody-phage library derived from blood of a convalescent SARS patient for antibodies complementary to CR3014. A novel mAb, CR3022, was identified that neutralized CR3014 escape viruses, did not compete with CR3014 for binding to recombinant S1 fragments, and bound to S1 fragments derived from the civet cat SARS-CoV-like strain SZ3. No escape variants could be generated with CR3022. The mixture of both mAbs showed neutralization of SARS-CoV in a synergistic fashion by recognizing different epitopes on the receptor-binding domain. Dose reduction indices of 4.5 and 20.5 were observed for CR3014 and CR3022, respectively, at 100\% neutralization. Because enhancement of SARS-CoV infection by subneutralizing antibody concentrations is of concern, we show here that anti-SARS-CoV antibodies do not convert the abortive infection of primary human macrophages by SARS-CoV into a productive one.

\section{Conclusions}

The combination of two noncompeting human mAbs CR3014 and CR3022 potentially controls immune escape and extends the breadth of protection. At the same time, synergy between CR3014 and CR3022 may allow for a lower total antibody dose to be administered for passive immune prophylaxis of SARS-CoV infection.

The Editors' Summary of this article follows the references. 


\section{Introduction}

Severe acute respiratory syndrome (SARS) is caused by a novel coronavirus (SARS-CoV) that spread in 2003 and 2004 from the Guangdong province of southern China to 32 countries in Asia, Europe, and North America, resulting in over 8,000 cases and 774 deaths [1,2]. The main epidemic was stopped in late 2003 through internationally coordinated public health measures including early isolation of SARS patients and quarantine of contacts, at considerable economic costs to the affected countries [3-5]. In 2003 and 2004 a number of isolated SARS cases occurred again in China and other Asian countries; some of these cases were linked to laboratory or unknown exposure, but others were community acquired and associated with exposure to the live game animal restaurant trade in Guangdong province [6,7]. SARSCoV-like viruses almost identical to a patient's isolate were found in palm civet cats investigated during the same period [7]. Phylogenetic analysis of approximately 100 SARS-CoV isolates from humans and civet cats collected from 2002 to 2004 revealed that SARS is a zoonotic disease that is evolving in palm civet and human hosts [7-9]. Furthermore, presumably asymptomatic infection with SARS-CoV-like coronaviruses has repeatedly occurred in wild animal handlers in Guangdong province several years before the SARS epidemic [9]. Recently, bats have been identified as an important natural reservoir of the virus [10]. It is therefore unlikely that the mass culling of civets cats performed in southern China is sufficient to prevent further spillover of SARS-CoV or SARS$\mathrm{CoV}$-like viruses to the human population.

In the search for a vaccine against SARS, neutralizing antibodies have been raised successfully in experimental animals through immunization with whole killed virus or recombinant vaccine constructs expressing the SARS-CoV glycoprotein spike (S) [11-13]. Correspondingly, studies of the immune responses in SARS patients have shown that the appearance of neutralizing antibodies coincides with a decrease of virus titers in serum, urine, stool, and nasopharyngeal secretions; in addition the beneficial effect of convalescent plasma in SARS patients has been reported [14-16]. Neutralizing antibodies against SARS-CoV generated through experimental vaccination or monoclonal antibody $(\mathrm{mAb})$ technology have repeatedly been shown in passive transfer experiments to protect mice from infection by reduction of viral replication [11,17-20]. In addition, the human mAb CR3014, generated by phage display, completely prevented lung pathology in the ferret model of SARS-CoV infection and abolished shedding of the virus in pharyngeal secretions [21]. CR3014 was shown to block interaction of the $\mathrm{S} 1$ subunit of the $\mathrm{S}$ protein with its cellular receptor ACE2 [22].

Because passive immunization using polyclonal sera has been reported to curb outbreaks of hepatitis $\mathrm{A}$ virus and to prevent infection with varicella-zoster virus, $\mathrm{mAb}$ prophylaxis may be an effective means of controlling a SARS outbreak [23,24]. To this end, it is important that a mAb product offer sufficient breadth of protection against all relevant strains of SARS-CoV and prevent the selection of neutralization escape variants in the patient. In this study we therefore address both of these issues and present the characteristics of a combination of CR3014 with a new SARS-CoV neutralizing human $\mathrm{mAb}$ that was isolated from a convalescent patient.
Because antibody-dependent enhancement of viral replication has been observed in macrophages for one member of the coronavirus family (feline infectious peritonitis virus), we also investigated whether a similar phenomenon occurs with SARS-CoV [25]. Infection of primary human macrophages with SARS-CoV has been reported to result in abortive infection with no infectious virus progeny produced [26]. We therefore studied whether virus infection in the presence of serial dilutions of CR3014 or serum from a convalescent SARS patient leads to productive virus infection.

\section{Methods}

\section{Human Monoclonal Antibodies}

The mAb CR3014 was isolated from a semisynthetic singlechain variable antibody fragment ( $\mathrm{scFv}$ ) phage display library, expressed as human IgG1 molecules and purified as described previously $[22,27]$. An immune $\mathrm{scFv}$ phage display library was constructed from lymphocytes of a convalescent SARS patient from Singapore essentially as described [28]. From this library, CR3022 scFv was selected for binding to UVinactivated SARS-CoV, essentially as described [22]. SARSCoV (Frankfurt 1 strain [FM1]) was prepared as described and UV-irradiated for $15 \mathrm{~min}$ (UVB radiation, $280-350 \mathrm{~nm} ; \lambda_{\max }$, $306 \mathrm{~nm})$ at $4{ }^{\circ} \mathrm{C}$. CR3022 $\mathrm{scFv}$ was converted into a human IgG1 format and expressed and purified as described. Antirabies mAb CRJA served as negative control.

\section{Virus Neutralization Assay and Determination of Antibody Potency}

Research involving SARS-CoV virus was performed under biosafety level 3 containment. SARS-CoV strain HKU-39849 at $2 \times 10^{3} \mathrm{TCID}_{50} / \mathrm{ml}$ in $100 \mu \mathrm{l}$ was mixed with an equal volume of serially diluted $\mathrm{mAb}$ in maintenance medium (MM, MEM supplemented with $1 \% \mathrm{v} / \mathrm{v}$ FCS) and incubated for $1 \mathrm{~h}$ at $37{ }^{\circ} \mathrm{C}$. Subsequently, the mixture was inoculated in octuplicate onto 96-well plate containing a $80 \%$ confluent culture of fetal rhesus kidney cells (FRhK-4; American Type Culture Collection, Manassas, Virginia, United States; \#CRL1688). The FRhK- 4 cells were cultured at $37^{\circ} \mathrm{C}$ and observed after 3-4 $\mathrm{d}$ for the development of CPE. The $\mathrm{mAb}$ concentrations required for $50 \%$ and $100 \%$ neutralization were calculated from two-fold dilution series according to the Spearman-Karber formula. To quantitatively compare the neutralizing potency of a CR3014/CR3022 combination with the individual potencies of the mAbs, they were mixed in an equimolar ratio and the $100 \%$ and $50 \%$ neutralization potency of a serial dilution of the mix was determined. The concepts of the combination index (CI) and dose reduction index (DRI) were used to quantify synergistic effects as described previously [29,30].

\section{Generation and Characterization of Neutralization Escape Variants}

Serial dilutions ranging from $10^{-1}$ to $10^{-8}$ of SARS-CoV strain HKU-39849 were incubated in the presence of a constant amount of CR3014 $(20 \mu \mathrm{g} / \mathrm{ml})$ or CR3022 $(60 \mu \mathrm{g} / \mathrm{ml})$, for $1 \mathrm{~h}$ at $37{ }^{\circ} \mathrm{C}$ and $5 \% \quad \mathrm{CO}_{2}$ before addition to wells containing FRhK-4 cells. The virus-mAb mixture was incubated with cells for $1 \mathrm{~h}$ at $37^{\circ} \mathrm{C}$ and $5 \% \mathrm{CO}_{2}$, then the virus was removed and the cells were washed twice with medium. Finally, cells were incubated for $2 \mathrm{~d}$ in the presence of the 
above concentrations of $\mathrm{mAb}$ in $0.5 \mathrm{ml}$ of medium. Supernatant of cells incubated with highest virus dilution showing CPE, containing the potential escape viruses, was harvested and stored at $4{ }^{\circ} \mathrm{C}$ until further use. Virus samples were freeze-thawed once, serial dilutions were prepared in medium and added to wells containing FRhK-4 cells, and the dilutions incubated for $1 \mathrm{~h}$ at $37{ }^{\circ} \mathrm{C}$ and $5 \% \mathrm{CO}_{2}$ in the presence of mAb. Wells were then overlaid with agarose containing mAbs at the above concentration and incubated for $3-5 \mathrm{~d}$ at $37{ }^{\circ} \mathrm{C}$ and $5 \% \quad \mathrm{CO}_{2}$. Individual escape virus plaques were picked using a Pasteur pipette and freezethawed once, and the escape viruses were amplified on FRhK4 cells. To identify possible mutations in the SARS-CoV spike protein of each of the escape viruses, the nucleotide sequence of the SARS-CoV S open reading frame (ORF) was determined. Viral RNA of each of the escape viruses and wild-type SARS-CoV virus was isolated and converted into cDNA by standard RT-PCR. Subsequently, the cDNA was used for nucleotide sequencing of the SARS-CoV S ORF in order to identify mutations. Secondly, the neutralization index was determined for each of the escape viruses. Therefore, each escape virus and wild-type SARS-CoV (100 TCID $\left._{50}\right)$ was incubated for $1 \mathrm{~h}$ at $37^{\circ} \mathrm{C}$ and $5 \% \mathrm{CO}_{2}$ with $\mathrm{mAb}$ at the above concentration before addition to FRhK- 4 cells. The virus was allowed to attach to the cells for $1 \mathrm{~h}$ at $37^{\circ} \mathrm{C}$ and $5 \% \mathrm{CO}_{2}$, after which the inoculum was removed and cells were washed twice with medium before being replenished with medium containing mAb. After a $2 \mathrm{~d}$ incubation at $37^{\circ} \mathrm{C}$ and $5 \% \mathrm{CO}_{2}$ the medium was harvested and the $\mathrm{TCID}_{50} / \mathrm{ml}$ of each virus was determined. The neutralization index was determined by subtracting the number of infectious virus particles (expressed as $\log \mathrm{TCID}_{50} / \mathrm{ml}$ ) produced in FRhK-4 cell cultures infected with virus in the presence of $\mathrm{mAb}$ from the number of infectious virus particles $\left(\log \mathrm{TCID}_{50} / \mathrm{ml}\right)$ produced in FRhK-4 cell cultures infected with virus alone. An index lower than 2.5 was considered evidence of escape.

\section{Recombinant SARS-CoV Glycoprotein Spike Fragments}

The generation of the plasmids encoding recombinant spike (S) fragments comprising residues 318-510 of the human SARS-CoV strains FM1, GZ02, Sin3408, Shanghai LY, GZ-C, Sino1-11, BJ302 clone 2, GD03T0013, GD01, and the palm civet cat derived strain SZ3 (AY304486), as well as expression and purification of the recombinant proteins have previously been described [22].

\section{Epitope Mapping using ELISA}

Direct ELISA using the recombinantly expressed $S$ fragment comprising amino acids 318-510 (S318-510) was performed with the mAbs as described [22]. Competition ELISA was performed as follows. Anti-Myc-captured S318-510 fragment of the Frankfurt 1 strain was incubated with nonsaturating amounts of biotinylated $\operatorname{IgG}$ in the presence or absence of competing IgG. Bound biotinylated IgG was detected with streptavidin-conjugated-HRP (BD Pharmingen, San Diego, California, United States). Alternatively, S318-510 was captured by CR3014 or CR3022, detected using a biotinylated CR3014 and CR3022, and developed as described above.

\section{BIAcore Analysis}

Surface plasmon resonance analyses were performed at 25 ${ }^{\circ} \mathrm{C}$ on a BIAcore3000 (Biacore AB, Uppsala, Sweden). CM5 sensorchips and running buffer HBS-EP were from Biacore AB. Recombinant S318-510 was immobilized to CM5 chips using an amine coupling procedure resulting in a response level of approximately 1,000 resonance units. Kinetic analysis was performed to determine the association rate constant $\left(k_{\mathrm{a}}\right)$, dissociation rate constant $\left(k_{\mathrm{d}}\right)$, and the affinity $\left(K_{\mathrm{D}}\right)$ of the mAbs. Therefore, a concentration series of $0.4-250 \mathrm{nM}$ IgG was prepared using two-fold dilutions in HBS-EP. Samples were injected in duplicate at a flow rate of $30 \mu \mathrm{l} / \mathrm{min}$ (injection time, $2 \mathrm{~min}$; dissociation time, $5 \mathrm{~min}$ ). The sensor chip surface was regenerated with a $5 \mu \mathrm{l}$ pulse of $5 \mathrm{mM} \mathrm{NaOH}$. Biacore evaluation software (BIAevaluation, version 3.2) was used to fit the association and dissociation curves of all concentrations injected.

\section{Immune Enhancement Assay of SARS-CoV Replication in Primary Human Macrophages}

Preparation of primary human monocytes/macrophages and their infection with SARS-CoV was performed as previously described [26]. To investigate the effect of subneutralizing doses of anti-SARS Abs on viral infection in macrophages, $300 \mu \mathrm{l}$ of serially diluted mAb in MM medium, convalescent serum from a SARS-CoV exposed individual, or serum from a healthy individual was mixed with $300 \mu \mathrm{l}$ of SARS-CoV. MM medium mixed with SARS-CoV served as the virus control. The virus $/ \mathrm{mAb}$ mixtures and virus/serum mixtures were incubated for $1 \mathrm{~h}$ at $37{ }^{\circ} \mathrm{C}$. Then, $250 \mu \mathrm{l}$ of the mixtures was added to duplicate wells containing macrophages. After $1 \mathrm{~h}$ of virus adsorption at $37^{\circ} \mathrm{C}$, the virus inoculum was removed, infected cells were washed with macrophage SFM culture medium and incubated in macrophage SFM medium supplemented with $0.6 \mu \mathrm{g} / \mathrm{ml}$ penicillin and $60 \mu \mathrm{g} / \mathrm{ml}$ streptomycin. Samples of the culture supernatants were collected at days $0,1,2,3,5$, and 7 postinfection and stored at $-70{ }^{\circ} \mathrm{C}$ for virus titration experiments. SARS$\mathrm{CoV}$ was titrated and the $\mathrm{TCID}_{50}$ determined essentially as described. RNA was isolated from infected macrophages at 6 and 24 hours postinfection using the RNeasy Mini kit (Qiagen, Valencia, California, United States) according to the manufacturer's instructions. Quantification of positiveand negative-strand viral RNA was performed by real-time quantitative RT-PCR targeting the ORF1b gene, as described previously [31]. The SARS-CoV RNA levels were normalized for the levels of $\beta$-actin mRNA.

\section{Results}

\section{All CR3014 Neutralization Escape Variants of SARS-CoV Display a P462L Mutation in the Spike Glycoprotein}

Full neutralization curves of wild-type SARS-CoV and one CR3014-neutralization escape virus with CR3014 and CR3022 are shown in Figure 1. All five neutralization escape variants were completely refractory to neutralization with CR3014. Sequencing of the complete spike gene of these variants isolated from two separate viral cultures $(n=5)$ revealed that all carried a single point mutation at amino acid position 462 (proline to leucine, P462L), which abolished binding of CR3014 to the recombinantly expressed receptor-binding domain (RBD) fragment (S318-510) displaying this mutation (Figure 2). This mutation has to date been observed neither in SARS-CoV isolates from human patients nor in SARS-CoVlike coronaviruses found in civet cats. In two independent 


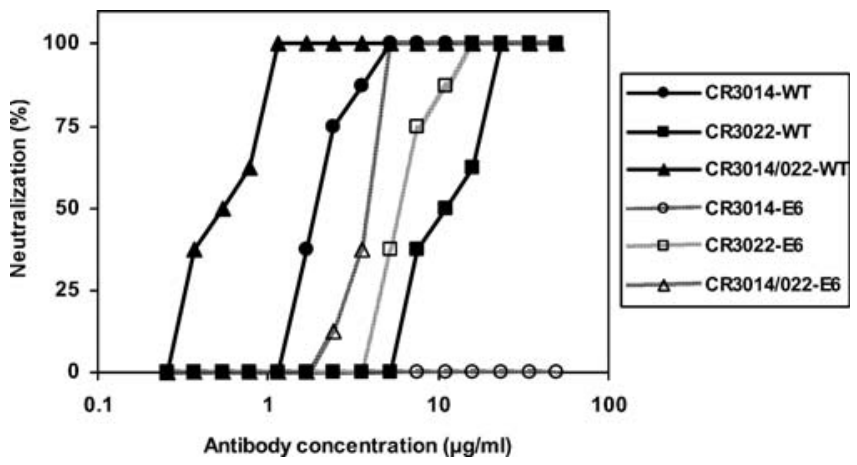

Figure 1. Neutralization of Wild-Type SARS-CoV and a CR3014Neutralization Escape Variant (E6) with mAbs CR3014 and CR3022 Individually and in Combination

Neutralization of $100 \mathrm{TCID}_{50}$ of each virus was performed in octuplicate. Data are also shown in Table 1.

DOI: 10.1371/journal.pmed.0030237.g001

experiments, repeated passage of SARS-CoV in the presence of up to $60 \mu \mathrm{g} / \mathrm{ml}$ CR3022 did not result in the generation of neutralization escape variants (unpublished data).

Human mAb CR3022 Neutralizes CR3014 Escape Variants of SARS-CoV by Binding Noncompetitively to the RBD of the Spike Glycoprotein

An antibody phage display library was constructed from RNA isolated from the lymphocytes of a convalescent SARS patient originating from Singapore. Antibody CR3022 was isolated which completely neutralized the SARS-CoV strain HKU-39849 and the CR3014 escape variants at a concentration of $23.5 \mu \mathrm{g} / \mathrm{ml}$ (Table 1). CR022 was shown in ELISA to bind noncompetitively with CR3014 to the recombinantly expressed RBD of the S glycoprotein of wild-type SARS-CoV (strain Frankfurt 1) and also to the mutated RBD (P462L) of the escape variants (Figures 2 and 3), which were completely

Table 1. Synergy of CR3014 and CR3022 for SARS-CoV Neutralization and Coverage of CR3014 Escape Viruses by CR3022

Virus

Calculation

Single $\mathrm{mAb}$ or Combination $(\mu \mathrm{g} / \mathrm{ml})$ CR3014 CR3022 CR3014

+ CR3022

\begin{tabular}{|c|c|c|c|c|}
\hline \multirow{6}{*}{$\begin{array}{l}\text { Wild-type } \\
\text { SARS-CoV }\end{array}$} & $100 \%$ neutralization $^{a}$ & 5.2 & 23.5 & $1.1+1.1$ \\
\hline & $50 \%$ neutralization $^{a}$ & 2.0 & 11.0 & $0.5+0.5$ \\
\hline & $\mathrm{Cl}_{100}$ & $-^{b}$ & $-^{b}$ & $0.27^{c}$ \\
\hline & $\mathrm{Cl}_{50}$ & $-^{\mathrm{b}}$ & $-^{\mathrm{b}}$ & $0.34^{c}$ \\
\hline & Mean $\mathrm{DRI}_{100}{ }^{\mathrm{d}}$ & 4.5 & 20.5 & $-^{\mathrm{b}}$ \\
\hline & Mean $\mathrm{DRI}_{50}{ }^{\mathrm{d}}$ & 3.7 & 20.5 & $-^{\mathrm{b}}$ \\
\hline \multirow{2}{*}{$\begin{array}{l}\text { CR3014 escape } \\
\text { virus (E6) }\end{array}$} & $100 \%$ neutralization $^{a}$ & $-^{\mathrm{e}}$ & 16 & 5.2 \\
\hline & $50 \%$ neutralization $^{\mathrm{a}}$ & $-^{\mathrm{e}}$ & 6.3 & 3.6 \\
\hline
\end{tabular}

${ }^{\text {aAll }}$ assays performed in octuplicate. Data are also shown in Figure 1.

${ }^{\mathrm{b}}$ Not applicable.

'Synergy is indicated when $\mathrm{Cl}<1$.

${ }^{\mathrm{d} D R I s}$ were measured by comparing the doses required to reach a given degree of virus neutralization when the antibodies were used alone and in combination.

${ }^{\mathrm{e}}$ At $50 \mu \mathrm{g} / \mathrm{ml}$ CR3014 no neutralization was observed.

DOI: 10.1371/journal.pmed.0030237.t001

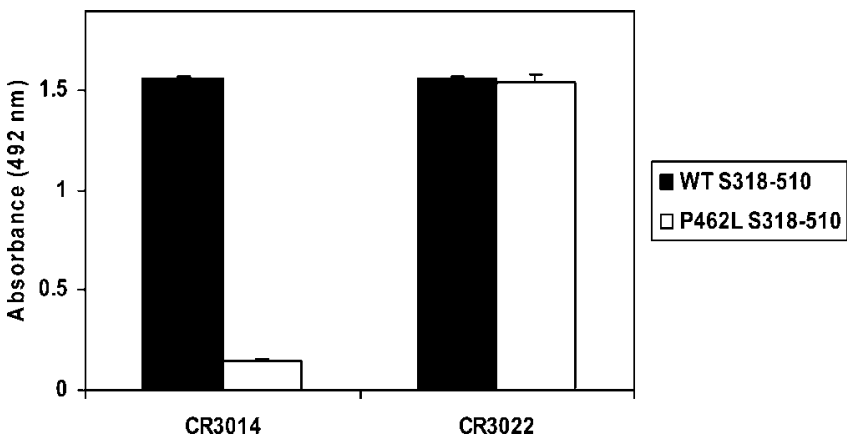

Figure 2. Binding of mAbs CR3014 and CR3022 to Recombinant WildType and P462L-Substituted S318-510 Fragments Analyzed by ELISA Bars represent the means \pm standard deviation. DOI: 10.1371/journal.pmed.0030237.g002

neutralized by $16 \mu \mathrm{g} / \mathrm{ml}$ of this $\mathrm{mAb}$. In contrast to CR3014, CR3022 did not prevent binding of a recombinant $S$ fragment composed of amino acids 1-565 to Vero cells (unpublished data). The sequences of the variable regions of the heavy and light chains of CR3022 were deposited at GenBank.

\section{CR3022 Shows Extended Reactivity with Recombinantly Expressed S Fragments of Different SARS-CoV Strains}

In addition to the fragments recognized by CR3014, CR3022 also binds to the RBDs of SARS-CoV-like isolate SZ3 isolated from a civet cat and from a human SARS-CoV with a mutation of asparagine to serine at amino acid 479 (N479S), which were not or only partially recognized by CR3014, respectively (Figure 4).

\section{CR3014 and CR3022 Neutralize SARS-CoV Synergistically}

To evaluate whether CR3014 and CR3022 would neutralize SARS-CoV in an additive or synergistic manner, we used the classic method of titrating the neutralizing potency of an equimolar mixture of the antibodies and comparing the dose response with that from neutralization assays performed with the individual antibodies (Figure 1). The data were analyzed by applying the median effect principle as formulated by Chou and Talalay [29]. A combination index (CI) of less than 1 , indicating synergistic neutralization, was observed in three independent experiments for both $50 \%$ and $100 \%$ neutralization of wild-type SARS-CoV (Table 1). As is evident from the DRIs, the mixture of antibodies reduced the required antibody dose especially for CR3022 considerably (DRI = 20.4). Interestingly, CR3014 also slightly enhanced neutralization of the escape viruses by CR3022 (Figure 1).

Simultaneous Binding of mAbs CR3014 and CR3022 to Recombinant S318-510 Fragment Does Not Change Their Affinities

To investigate changes of affinities as a possible mechanism of synergy, the $K_{\mathrm{D}}$ for CR3014 and CR3022 binding sequentially or simultaneously to recombinant RBD was investigated. The individual $K_{\mathrm{D}}$ values for CR3014 and CR3022 were $16.3 \mathrm{nM}$ and $0.125 \mathrm{nM}$, respectively; for the antibodies binding simultaneously was $5.71 \mathrm{nM}$; and for binding of CR3014 to CR3022-saturated S318-510 was 14.8 nM. Compared to the dose reduction indices of 4.5 and 20.5 for CR3014 and CR3022, respectively, neither simultaneous nor sequential binding of the mAbs resulted in changes of $K_{\mathrm{D}}$ 
A
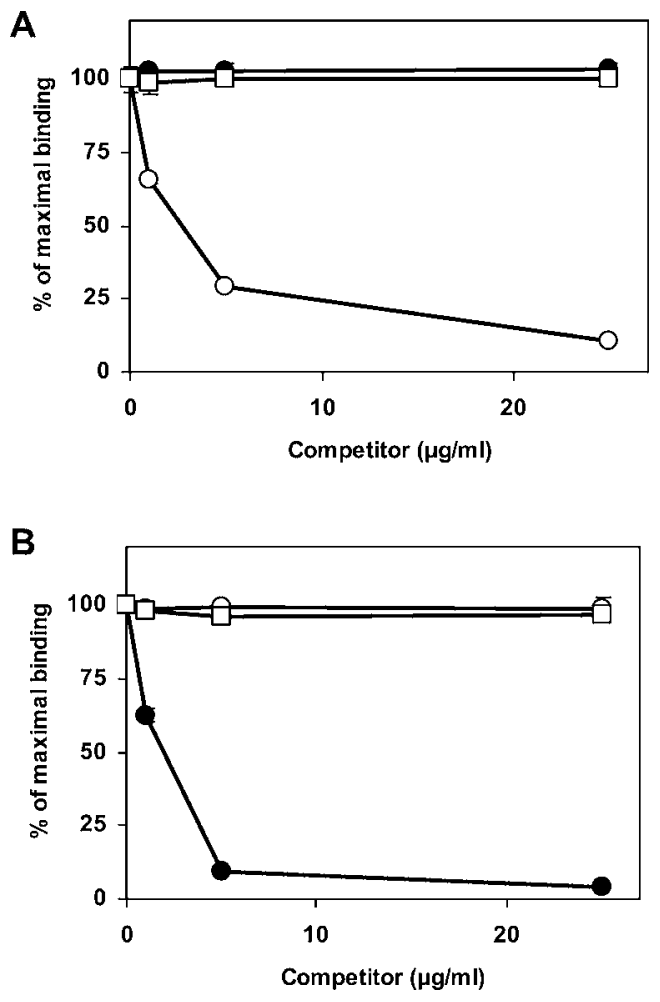

Figure 3. Competition ELISA on Immobilized S318-510

Binding of biotinylated CR3014 (A) and CR3022 (B) was analyzed in the presence of competitor CR3014 (open circles), CR3022 (closed circles), and control $\mathrm{mAb}$ (open squares). Binding is expressed as percentage of binding without competitor.

DOI: 10.1371/journal.pmed.0030237.g003

that could explain their synergistic neutralizing action through cooperative binding.

\section{SARS-CoV Does Not Replicate in Human Macrophages in} the Presence of mAb CR3014 or Convalescent Serum

SARS-CoV did not replicate to measurable titers after day 2 on macrophages in the absence or presence of serial dilutions of mAb CR3014, a control mAb, or serum from a convalescent patient (unpublished data). Figure 5 shows the detection of SARS-CoV positive $(\mathrm{P})$ or negative $(\mathrm{N})$ strand RNA (replication intermediate) by RT-PCR in the same assay. Positive-strand RNA is detectable at 6 and $24 \mathrm{~h}$ postinfection, indicating uptake of virus by the macrophage. In the presence of $2.8 \times 10^{-5}$ to $2.8 \times 10^{-3} \mu \mathrm{g} / \mathrm{ml}$ of CR3014 a slight increase in virus uptake into macrophages is suggested by the increased copy number of positive-strand RNA (Figure 5). In contrast, negative-strand RNA, which indicates viral replication, is detectable at much lower levels that are constant over time, with no difference between the virus incubated with CR3014 or control antibody. Taken together, these results show that with or without monoclonal or polyclonal antibody, macrophages take up SARS-CoV, but this uptake does not lead to the productive virus replication and release of infectious virus.

\section{Discussion}

Our results show that SARS-CoV can be neutralized synergistically by human mAbs targeting the receptor-binding domain of the virus. The combination of two mAbs expanded the breadth of protection and controlled potential immune escape variants while reducing the total antibody concentration required to neutralize the virus. In view of the proven efficacy of passive prophylaxis of SARS-CoV infection in animal models using single mAbs, our data provide a rationale to develop cocktails of mAbs for human SARS prophylaxis.

Although the SARS epidemic of 2003 was successfully contained, the risk of its re-emergence remains from its natural animal reservoir, from intermediate hosts such as civet cats in live animal markets, or from laboratory associated infections. The re-emergence and community spread of SARS in Beijing in February 2004 required the quarantine of large numbers of contacts; the social and economic consequences of such measures are considerable. The availability of prophylactic and therapeutic measures against SARS-CoV would greatly assist the control of any

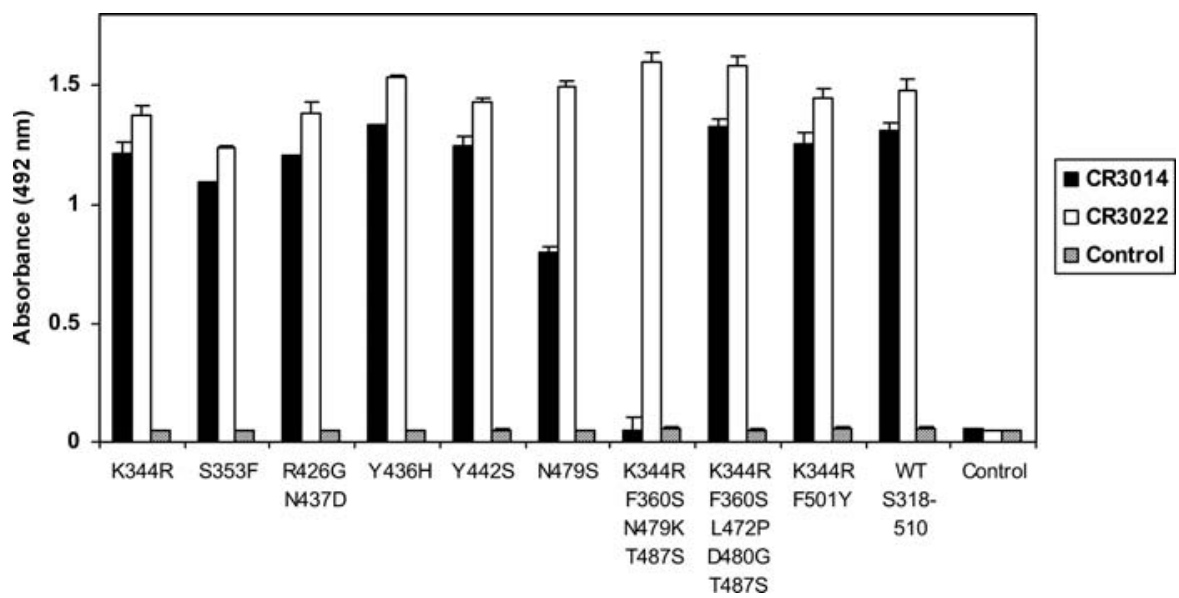

Figure 4. Binding of Human mAbs to S318-510 Fragments in ELISA

Wild-type and variant fragments were synthesized according to published sequences of SARS-CoV strains. Wild-type S318-510 from strain Frankfurt 1 , variant fragments from strains GZ02 (K344R), Sin3408 (S353F), Shanghai LY (R426G and N437D), GZ-C (Y436H), Sino1-11 (Y442S), BJ302 cl. 2 (N479S), SZ3 (K344R, F360S, N479K, and T487S), GD03T0013 (K344R, F360S, L472P, D480G, and T487S), and GD01 (K344R and F501Y). Bars represent the means \pm standard deviation.

DOI: 10.1371/journal.pmed.0030237.g004 

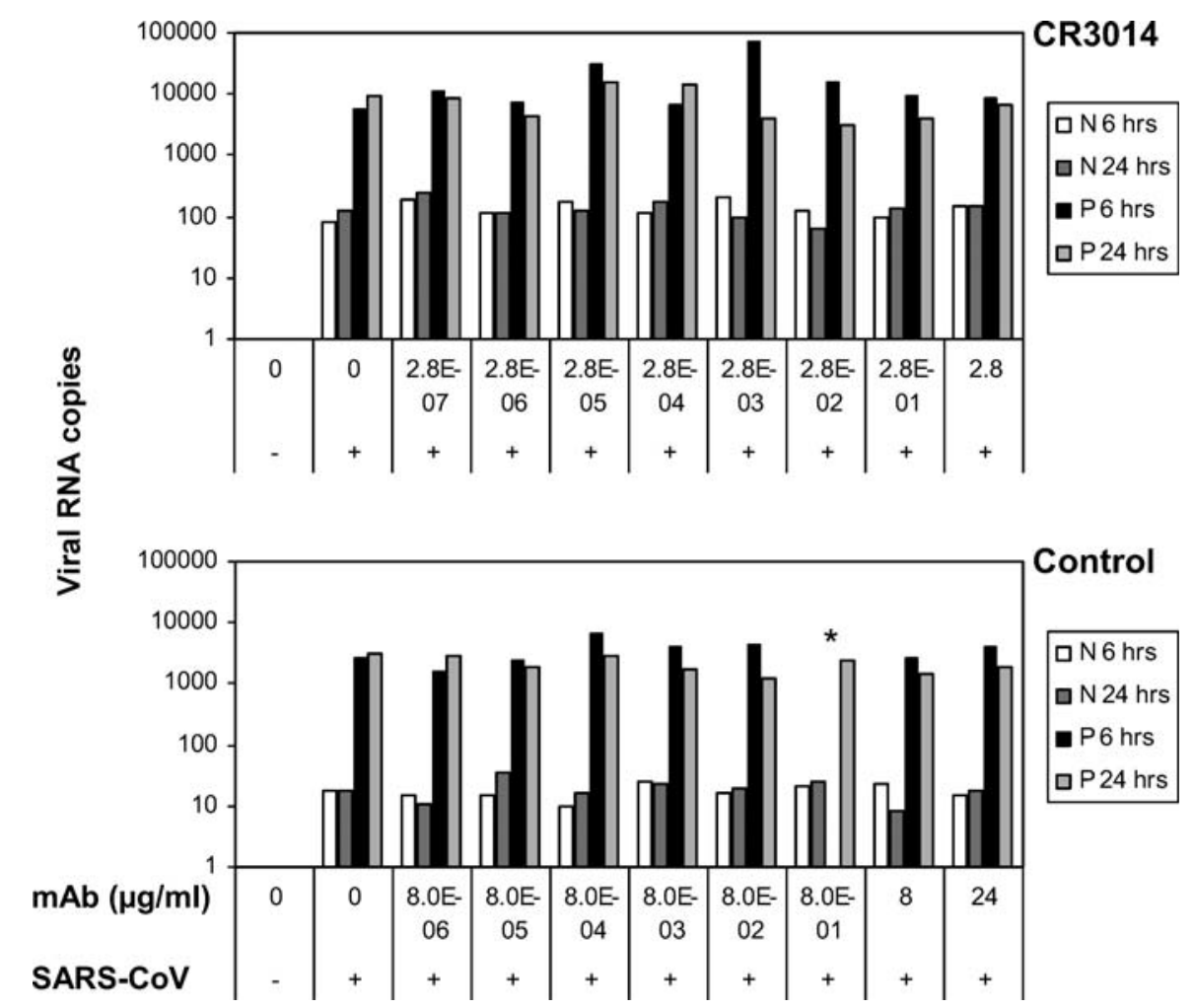

Figure 5. Infection of Differentiated Human Macrophages with SARS-CoV (HKU-39849) in the Presence of CR3014 or a Control mAb

One representative experiment of three independent experiments is shown. Total RNA was extracted at 6 and 24 hours postinfection, and the copy number of positive (P) and negative (N) strand RNA of SARS-CoV ORF1b was determined by real-time quantitative RT-PCR and normalized for the levels of $\beta$-actin mRNA. The bars represent mean of duplicate viral load titrations. In the control experiment, ${ }^{*}$ indicates an aberrant result.

DOI: 10.1371/journal.pmed.0030237.g005

future re-emergence of the virus, and their development therefore remains a high priority [32].

With respect to vaccine development, considerable progress has been made in understanding the immune response against the virus and defining correlates of protection. Patients with high viral loads and shedding of SARS-CoV in pharyngeal secretions have elevated mortality [33]. Correspondingly, the development of neutralizing antibody titers correlates with a decrease of virus titers in serum, urine, stool, and nasopharyngeal secretions [15]. Progress has also been made in understanding the target of the neutralizing immune response through immunization with whole killed SARS-CoV and recombinant vectors expressing the $\mathrm{S}$ glycoprotein and other structural proteins [11-13]. Neutralizing antibodies seem to be predominantly directed against a domain of the S1 subunit of the spike protein, defined by amino acids 318510 , which is responsible for interaction of the virus with its cellular receptor ACE2 [34-37]. Mapping of this RBD using a panel of mouse mAbs has led to the identification of six distinct neutralizing epitopes, which are all conformationdependent [38]. The neutralizing potency of the mAb correlated directly with their ability to block the RBD-ACE2 interaction in recombinant assays; however, several neutralizing mAbs were also identified that bind to two distinct epitopes of the RBD without inhibiting the interaction with ACE2.

The concept of using polyclonal or monoclonal antibodies with neutralizing activity against SARS-CoV for passive immunization to control both development of severe disease and transmission from human to human of the virus is based on several observations. The use of convalescent serum in SARS patients was reported to be associated with possible benefit and in any event was not associated with adverse effects $[14,16]$. In consequence, commercial production of SARS antiserum from human donors has been initiated in China [39]. Passive transfer of immune serum generated through immunization of animals with whole killed virus or vector-expressed full-length $\mathrm{S}$ or $\mathrm{S}$ fragments has reduced viral replication in a mouse model of SARS-CoV infection $[11,18]$. Human mAbs have been generated through phage display, immortalization of human B-cells from SARSpatients, or immunization of transgenic mice, and were shown to display protective efficacy in the mouse model $[17,19,20]$. In addition, the human mAb CR3014 reduced SARS-CoV replication in the lungs of infected ferrets, completely prevented the development of lung lesions, and abolished viral shedding in the pharyngeal secretions of the animals [21]. Because SARS-CoV is spread by the respiratory and the fecal-oral route, the observation that passive immunization is successful in controlling outbreaks of hepatitis A virus and protecting against varicella-zoster and respiratory syncytial virus infection argues for the feasibility of an emergency immune prophylaxis during a SARS outbreak $[23,24,40]$.

Monoclonal antibody prophylaxis against SARS must meet certain criteria to be effective. The breadth of protection of a single mAb may not be sufficient to protect against all clinically relevant strains of the virus, and it has been 
suggested that genotyping of SARS-CoV in case of a new outbreak may be required to select for optimally neutralizing mAbs [19]. A comprehensive analysis of the variability of approximately 100 full-length genomes of SARS-CoV isolates obtained from human patients and civet cats between 2002 and 2004 revealed that the $\mathrm{S}$ glycoprotein, especially the RBD, is under strong positive selective pressure during the transition from animal-to-animal to human-to-human transmission, because of differences in the ACE2 receptors of civet cats and humans [7]. The highest variability of the RBD is observed within the group of SARS-CoV-like viruses isolated from animals, with no data as yet available concerning the receptor specificity of the newly discovered bat-CoV [10]. Interestingly, patients infected with SARS-CoV-like viruses had a milder course of disease and did not transmit the viruses to other persons, presumably because of insufficient adaptation of the civet cat virus RBD to human ACE2, which is required for productive infection of human cell lines $[19,41,42]$. The RBD of SARS-CoV isolates from the next SARS epidemic will therefore likely be very similar to the isolates from 2003. The RBD of human SARS-CoV isolates is highly conserved and alignment of 114 sequences published in GenBank revealed only eight different $S$ sequences not identical to the FM1 strain [22]. Of all human isolates SARSCoV-like isolate GD03T0013, which was obtained from a patient in 2003, shows the highest RBD divergence and closest relatedness to civet cat strains [7]. Human mAb CR3014 binds well to recombinantly expressed RBDs representing seven of the RBD variants, including GD03T0013, but less to a variant with a N479S mutation found in human isolate BJ302 cl.2, and not at all to an RBD derived from the civet cat SARS-CoV-like isolate SZ3. Antibody CR3022, derived by phage display from a convalescent SARS patient, binds well to the latter two variants in addition to the others. A combination of CR3014 and CR3022 may therefore offer sufficient protection not only against SARS-CoV strains but also against SARS-CoVlike viruses originating from civet cats.

Viral replication in the presence of a mAb, especially at subneutralizing concentrations, carries the risk of selecting neutralization escape variants. We therefore analyzed escape variants of SARS-CoV strain HKU-39849 generated under selective pressure of CR3014 or CR3022, which was unsuccessful for the latter. All CR3014 escape variants had the same single amino acid exchange in the RBD (P462L), which has not been reported in any SARS-CoV or SARS-CoV-like virus to date. This variant was successfully neutralized with CR3022, extending the breadth of protection of this antibody combination from naturally occurring variants also to possible CR3014 immune escapes. A similar strategy was previously pursued to develop a mAb product for postexposure prophylaxis of rabies [43]. Because neutralization escape in vitro may not accurately reflect the in vivo situation, the CR3014/CR3022 combination needs to be tested at subneutralizing concentrations in animal models of SARS-CoV infection.

Further investigation of the CR3014/CR3022 combination revealed that the antibodies neutralize wild-type SARS-CoV synergistically in vitro, with DRIs of about four and 20 for the two mAbs, respectively. Synergism of neutralizing mAbs has not yet been reported for SARS-CoV, but was observed for combinations of two, three, or four mAbs directed against different epitopes on the HIV-1 envelope glycoprotein, leading to a two- to ten-fold increase of neutralization titers $[30,44,45]$. Mechanistically, cooperative binding of mAbs may induce conformational changes in the antigen thereby altering affinities (allosteric effect), lead to intermolecular interaction of bivalent antibodies, or result in interaction of the Fc regions of antibodies brought into close contact [46]. As determined by ELISA, CR3014 and CR3022 bind simultaneously to the RBD of the S1 subunit of the glycoprotein $\mathrm{S}$ of SARS-CoV. However, measuring separate, sequential, and simultaneous binding of the mAbs in Biacore did not reveal enhanced affinity of the antibody mixture over the individual affinities, especially for CR3022. Another possible explanation for synergism could be increased breadth of protection against different quasispecies of a viral isolate [30]. Heterogeneous sequences have been detected through direct sequencing of SARS-CoV RNA recovered from single patient samples, and adaptive mutations induced by repeated cell culture passage have been reported [47-49]. It should therefore be formally investigated whether SARS-CoV quasispecies formation in cell culture may influence the outcome of virus neutralization assays. Lastly, CR3022 could interfere with binding of the $\mathrm{S} 1$ subunit to a known or unknown coreceptor of the virus [50]. The mechanism by which the two mAbs neutralize SARS-CoV synergistically therefore remains presently elusive.

It was previously shown that CR3014 protects ferrets from challenge with SARS-CoV at a dose of $10 \mathrm{mg} / \mathrm{kg}$ by completely preventing lung pathology and abolishing shedding of the virus [21]. This antibody dose compares well with the required dosage of Palivizumab (15 mg/kg), which protects at-risk infants from infection with respiratory syncytial virus and is currently the only licensed antiviral monoclonal antibody [40]. However, the required amount of CR3014 for protecting a standard $70 \mathrm{~kg}$ adult is relatively high, and it would be desirable to use a lower dose for economic reasons. Furthermore, the even lower potency of CR3022 precludes its use as a stand-alone prophylaxis. Therefore, the observed four- to twenty-fold dose reduction of the individual mAbs in the CR3014/CR3022 mixture may hold an attractive option to reduce the total antibody dose required for neutralizing the virus in vivo while at the same time expanding the breadth of protection.

In this study, we also addressed the potential problem of antibody-dependent enhancement (ADE), which is a wellrecognized phenomenon observed in infections with another coronavirus, feline infectious peritonitis virus. Both immunization and passive transfer of antibody was shown to mediate this phenomenon and mAbs have been used to map neutralizing and enhancing epitopes on the spike glycoprotein of feline infectious peritonitis virus [25,51]. There is no direct evidence of ADE linked to SARS-CoV infection in humans to date, and infection of human macrophages with SARS-CoV was previously shown to be abortive [25]. However, it was recently shown, in a viral pseudotype assay expressing the full-length spike glycoproteins of SARS-CoVlike viruses, that these cannot be neutralized with either homologous or heterologous mouse immune sera, and that both the sera and human mAbs neutralizing SARS-CoV enhance infectivity of the pseudotype for the human adenocarcinoma cells used as indicator system [34]. Given that ADE in feline infectious peritonitis virus infection is mediated by increased macrophage uptake of virus in the 
presence of neutralizing antibody, we performed human macrophage infectivity assays in the presence of CR3014 and human convalescent serum. In this type of assay, ADE of Dengue and Ross River virus infection has previously been demonstrated [52]. The addition of varying concentrations of CR3014 or convalescent SARS serum to SARS CoV did not convert the abortive infection into a productive one, reducing the likelihood that $\mathrm{ADE}$ will be observed in vivo after passive immunization.

In conclusion, we propose that a combination of neutralizing mAbs targeting the RBD of SARS-CoV has the potential to control SARS-CoV infection with a high level of efficacy and safety, and possibly at reduced economic cost. Isolation of suspected SARS cases and quarantine of exposed contacts have proved effective in controlling epidemics. However, the direct and indirect costs involved in quarantine measures are very substantial [4]. Monoclonal antibody prophylaxis (ring vaccination) in case of a SARS outbreak may prove more cost effective.

\section{Supporting Information}

Alternative Language Abstract S1. Chinese Translation of the Abstract.

Found at DOI: 10.1371/journal.pmed.0030237.sd001 (21 KB DOC).

\section{Accession Numbers}

The GenBank (http://www.ncbi.nlm.nih.gov) accession number of SARS-CoV strain HKU-39849 is AY278491. The sequences of the CR3022 variable regions of the heavy and light chains are deposited in GenBank under accession numbers DQ168569 and DQ168570, respectively.

\section{Acknowledgments}

Author contributions. JtM, ENvdB, JdK, and JG designed the study. $\mathrm{AQB}$ built the immune library, and $\mathrm{ENvdB}$ and $\mathrm{FC}$ isolated $\mathrm{mAb}$ CR3022. WP and HWD designed and performed virus neutralization experiments. JAB designed and analyzed the synergy experiments, which were performed by CSWL, CYC, and WP. ENvdB and FC constructed the recombinant spike fragments and tested their binding to mAbs. EvD designed and performed Biacore experiments. LLMP, WEM, CSWL, CYC, and JSMP designed and performed the rescue of the neutralization escape viruses and macrophage infection assays. VTC recruited the patient whose lymphocytes were used for library construction to generate the monoclonal antibody CR3022. JtM, ENvdB, LLMP, WEM, CYC, AQB, JAB, EvD, WP, HWD, VTC, JdK, JSMP, and JG analyzed and interpreted the data and contributed to writing the paper.

\section{References}

1. Drosten C, Gunther S, Preiser W, van der Werf S, Brodt HR, et al. (2003) Identification of a novel coronavirus in patients with severe acute respiratory syndrome. N Engl J Med 348: 1967-1976.

2. Peiris JS, Guan Y, Yuen KY (2004). Severe acute respiratory syndrome. Nat Med 10: S88-S97.

3. Donnelly CA, Fisher MC, Frazer C, Ghani AC, Riley S, et al. (2004). Epidemiological and genetic analysis of severe acute respiratory syndrome. Lancet Infect Dis 4: 672-683.

4. Gupta AG, Moyer CA, Stern DT (2005) The economic impact of quarantine: SARS in Toronto as a case study. J Infect 50: 386-393.

5. The Conference Board of Canada (2003) The economic impact of SARS. Available: http://www.conferenceboard.ca/documents.asp? rnext=539. Accessed 7 February 2006.

6. Liang G, Chen Q, Xu J, Liu Y, Lim W, et al. (2004) Laboratory diagnosis of four recent sporadic cases of community-acquired SARS, Guangdong Province, China. Emerg Infect Dis 10: 1774-1781.

7. Song HD, Tu CC, Zhang GW, Wang SY, Zheng K, et al. (2005) Crossevolution of severe acute respiratory syndrome coronavirus in palm civet and human. Proc Natl Acad Sci U S A 102: 2430-2435.

8. Chinese SARS Molecular Epidemiology Consortium (2004) Molecular evolution of the SARS coronavirus during the course of the SARS epidemic in China. Science 303: 1666-1669.

9. Guan Y, Zheng BJ, He YQ, Liu XL, Zhuang ZX, et al. (2003) Isolation and characterization of viruses related to the SARS coronavirus from animals in southern China. Science 302: 276-278.

10. Lau SKP, Woo PCY, Li KSM, Huang Y, Tsoi H-W, et al. (2005). Severe acute respiratory syndrome coronavirus-like virus in Chinese horseshoe bats. Proc Natl Acad Sci U S A 102: 14040-14045.

11. Bisht H, Roberts A, Vogel L, Bukreyev A, Collins PL, et al. (2004) Severe acute respiratory syndrome coronavirus spike protein expressed by attenuated vaccinia virus protectively immunizes mice. Proc Natl Acad Sci U S A 101: 6641-6646.

12. Buchholz UJ, Bukreyev A, Yang L, Lamirande EW, Murphy BR, et al. (2004) Contributions of the structural proteins of severe acute respiratory syndrome coronavirus to protective immunity. Proc Natl Acad Sci U S A 101: 9804-9809.

13. Bukreyev A, Lamirande EW, Buchholz UJ, Vogel LN, Elkins WR, et al. (2004) Mucosal immunization of African green monkey (Cercopithecus aethiops) with an attenuated parainfluenza virus expressing the SARS coronavirus spike protein for the prevention of SARS. Lancet 363: 2122-2127.

14. Burnouf T, Radosevich M (2003) Treatment of severe acute respiratory syndrome with convalescent plasma. Hong Kong Med J 9: 309-310.

15. Li G, Chen X, Xu A (2003) Profile of specific antibodies to the SARSassociated coronavirus. N Engl J Med 349: 508-509.

16. Wong S, Dai D, Wu AK, Sung JJ ( 2003) Treatment of severe acute respiratory syndrome with convalescent plasma. Hong Kong Med J 9: 199201.

17. Greenough TC, Babcock GJ, Roberts A, Hernandez HJ, Thomas WD, et al. (2005) Development and characterization of a severe acute respiratoryassociated coronavirus-neutralizing human monoclonal antibody that provides effective immunoprophylaxis in mice. J Inf Dis 191: 507-514.

18. Subbarao K, McAuliffe J, Vogel L, Fahle G, Fischer S, et al. (2004) Prior infection and passive transfer of neutralizing antibody prevent replication of severe acute respiratory syndrome coronavirus in the respiratory tract of mice. J Virol 78: 3572-3577.

19. Sui J, Li W, Roberts A, Matthews LJ, Murakami A, et al. (2005) Evaluation of human monoclonal antibody 80R for immunoprophylaxis of severe acute respiratory syndrome by an animal study, epitope mapping, and analysis of spike variants. J Virol 79: 5900-5906.

20. Traggiai E, Becker S, Subbarao K, Kolesnikova L, Uematsu Y, et al. (2004) An efficient method to make human monoclonal antibodies from memory B cells: Potent neutralization of SARS coronavirus. Nat Med 10: 871-875.

21. ter Meulen J, Bakker AB, van den Brink EN, Weverling GJ, Martina BE, et al. (2004) Human monoclonal antibody as prophylaxis for SARS coronavirus infection in ferrets. Lancet 363: 2139-2141.

22. van den Brink EN, ter Meulen J, Cox F, Jongeneelen MA, Thijsse A, et al. (2005) Molecular and biological characterization of human monoclonal antibodies binding to the spike and nucleocapsid proteins of severe acute respiratory syndrome coronavirus. J Virol 79: 1635-1644.

23. Pavia AT, Nielsen L, Armington L, Thurman DJ, Tierney E, et al. (1990) A community-wide outbreak of hepatitis A in a religious community: Impact of mass administration of immune globulin. Am J Epidemiol 131: 10851093.

24. Advisory Committee on Immunization Practices (ACIP) Centers for Disease Control and Prevention (1996) Prevention of varicella: Recommendations of the Advisory Committee on Immunization Practices (ACIP) Centers for Disease Control and Prevention. MMWR Recomm Rep 45: 1-36.

25. Corapi WV, Olsen CW, Scott FW (1992) Monoclonal antibody analysis of neutralization and antibody-dependent enhancement of feline infectious peritonitis virus. J Virol 66: 6695-6705.

26. Cheung CY, Poon LL, Ng IH, Luk W, Sia SF, et al. (2005) Cytokine responses in severe acute respiratory syndrome coronavirus-infected macrophages in vitro: Possible relevance to pathogenesis. J Virol 79: 7819-7826.

27. de Kruif J, Boel E, Logtenberg T (1995) Selection and application of human single chain Fv antibody fragments from a semi-synthetic phage antibody display library with designed CDR3 regions. J Mol Biol 248: 97-105.

28. Kramer RA,, Marissen WE, Goudsmit J, Visser TJ, Clijsters-Van der Horst $\mathrm{M}$, et al. (2005) The human antibody repertoire specific for rabies virus glycoprotein as selected from immune libraries. Eur J Immunol 35: $2131-$ 2145.

29. Chou TC, Talalay P (1984) Quantitative analysis of dose-effect relationships: The combined effects of multiple drugs or enzyme inhibitors. Adv Enzyme Regul 22: 27-55.

30. Zwick MB, Wang M, Poignard P, Stiegler G, Katinger H, et al. (2001) Neutralization synergy of human immunodeficiency virus type 1 primary isolates by cocktails of broadly neutralizing antibodies. J Virol 75: 1219812208 .

31. Poon LL, Chan KH, Wong OK, Cheung TK, Ng I, et al. (2004) Detection of SARS coronavirus in patients with severe acute respiratory syndrome by conventional and real-time quantitative reverse transcription-PCR assays. Clin Chem 50: 67-72

32. La Montagne JR, Taylor SL, Turnbull RJ, and the SARS research working group co-chairs (2004) Severe acute respiratory syndrome: Developing a research response. J Infect Dis 189: 642-647.

33. Tsang OT, Chau TN, Choi KW, Tso EY, Lim W, et al. (2003) Coronavirus- 
positive nasopharyngeal aspirate as predictor for severe acute respiratory syndrome mortality. Emerg Infect Dis 9: 1381-1387.

34. Yang ZY, Werner HC, Kong WP, Leung K, Traggiai E, et al. (2005) Evasion of antibody neutralization in emerging severe acute respiratory syndrome coronaviruses. Proc Natl Acad Sci U S A 102: 797-801.

35. Wong SK, Li W, Moore MJ, Choe H, Farzan M (2004) A 193-amino acid fragment of the SARS coronavirus S protein efficiently binds angiotensinconverting enzyme 2. J Biol Chem 279: 3197-3201.

36. He Y, Zhu Q, Liu S, Zhou Y, Yang B, et al. (2005) Identification of a critical neutralization determinant of severe acute respiratory syndrome (SARS)associated coronavirus: Importance for designing SARS vaccines. Virology 334: 74-82.

37. Wang S, Chou TW, Sakhatskyy PV, Huang S, Lawrence JM, et al. (2005) Identification of two neutralizing regions on the severe acute respiratory syndrome coronavirus spike glycoprotein produced from the mammalian expression system. J Virol 79: 1906-1910.

38. He Y, Hu L, Siddiqui P, Zhou Y, Jiang S (2005) Receptor-binding domain of severe acute respiratory syndrome coronavirus spike protein contain multiple conformation-dependent epitopes that induce highly potent neutralizing antibodies. J Immunol 174: 4908-4915.

39. Zhang Z, Xie YW, Hong J, Zhang X, Kwok SY, et al. (2005) Purification of severe acute respiratory syndrome hyperimmune globulins for intravenous injection from convalescent plasma. Transfusion 45: 1160-1164.

40. Meissner HC, Long SS (2003) Revised indications for the use of Palivizumab and respiratory syncytial virus immune globulin intravenous for the prevention of respiratory syncytial virus infection. Pediatrics 112: 1447-1441.

41. Li W, Zhang C, Sui J, Kuhn JH, Moore MJ, et al. (2005) Receptor and viral determinants of SARS-coronavirus adaptation to human ACE2. EMBO J 24 1634-1643

42. Qu X, Hao P, Song XJ, Jiang SM, Liu YX, et al. (2005) Identification of two critical amino acid residues of the severe acute respiratory syndrome coronavirus spike protein for its variation in zoonotic tropism transition via a double substitution strategy. J Biol Chem 280: 29588-29595.
43. Bakker AB, Marissen WE, Kramer RA, Rice AB, Weldon WC, et al. (2005) Novel human monoclonal antibody combination effectively neutralizing natural rabies virus variants and individual in vitro escape mutants. J Virol 79: $9062-9068$

44. Laal S, Burda S, Gorny MK, Karwowska S, Buchbinder A, et al. (1994) Synergistic neutralization of human immunodeficiency virus type 1 by combinations of human monoclonal antibodies. J Virol 68: 4001-4008.

45. Li A, Baba TW, Sodroski J, Zolla-Pazner S, Gorny MK, et al. (1998) Synergistic neutralization of simian-human immunodeficiency virus SHIV$\mathrm{vpu}^{+}$by triple and quadruple combinations of human monoclonal antibodies and high-titer anti-human immunodeficiency virus type 1 immuoglobulins. J Virol 72: 3235-3240.

46. Klonisch T, Panayotou G, Edwards P, Jackson AM, Berger P, et al. (1996) Enhancement in antigen binding by a combination of synergy and antibody capture. Immunology 89: 165-171.

47. Xu D, Zhang Z, Wang FS (2004) SARS-associated coronavirus quasispecies in individual patients. N Engl J Med 350: 1366-1377.

48. 48. Liu J, Lim SL, Ruan Y, Ling AE, Ng LFP, et al. (2005) SARS transmission pattern in Singapore reassessed by viral sequence variation analysis. PLoS Med 2: 162-168.

49. Poon LLM, Leung CSW, Yuen KY, Guan Y, Peiris JSM (2005) Recurrent mutations associated with isolation and passage of SARS coronavirus in cells from non-human primates. J Med Virol 9999: 1-6.

50. Jeffers SA, Tusell SM, Gillim-Ross L, Hemmila EM, Achebach JE, et al (2004) CD209L (L-SIGN) is a receptor for severe acute respiratory syndrome coronavirus. Proc Natl Acad Sci U S A 101: 15748-15753.

51. Klepfer S, Reed AP, Martinez M, Bhogal B, Jones E, et al. (1995) Cloning and expression of FECV spike gene in vaccinia virus. Immunization with FECV S causes early death after FIPV challenge. Adv Exp Med Biol 380: 235-241.

52. Takada A, Kawaoka Y (2003) Antibody-dependent enhancement of viral infection: Molecular mechanisms and in vivo implications. Rev Med Virol 13: 387-398

\section{Editors' Summary}

Background. Late in 2002, severe acute respiratory syndrome (SARS) emerged in the Guangdong province of China. In February 2003, an infected doctor from the province carried this new viral threat to human health to Hong Kong. Here, people staying in the same hotel caught the disease and took it to other countries. SARS was on the move, hitching lifts with international travellers. Because the virus responsible for SARS-SARS-CoV—spread by close person-to-person contact and killed $10 \%$ of the people it infected, health experts feared a world-wide epidemic. This was avoided by the World Health Organization issuing a global alert and warning against unnecessary travel to affected areas and by public-health officials isolating patients and their close contacts. By July 2003, the first SARS epidemic was over. 8,098 people had been infected; 774 people had died. Since then, sporadic cases of SARS have been contained locally.

Why Was This Study Done? The first epidemic of SARS was caused by an animal virus that became adapted to spread between people. There is no reason this process won't be repeated. If it is, stringent quarantine measures could again prevent a global epidemic, but at considerable economic cost. What is needed is a way to prevent SARS developing in healthy people who have been exposed to SARS-CoV and to treat sick people so that they are less infectious and can fight the virus. In this study, researchers have been investigating "passive immunization" as a way to limit SARS epidemics. In passive immunization, short-term protection against illness is achieved by injecting antibodies-proteins that recognize specific molecules (called antigens) on foreign organisms such as bacteria and viruses and prevent those organisms from causing disease. Antibodies for passive immunization can be isolated from blood taken from people who have had SARS, or they can be manufactured as so-called "human monoclonal antibodies" in a laboratory. One of these human monoclonal antibodies-CR3014-had been previously made and shown to prevent lung damage in ferrets infected with SARS-CoV and to stop the infected animals from infecting others. But for effective disease prevention in people, a single monoclonal antibody might not be enough. There are strains of SARS-CoV that CR3014 does not recognize and therefore cannot act against. Also, the virus can alter the antigen recognized by CR3014 when it is grown at a low antibody concentration, producing so-called escape variants; if this happens CR3014 can no longer prevent these escape variants from killing human cells.
What Did the Researchers Do and Find? The researchers tested how well a combination of two monoclonal antibodies controlled SARS-CoV killing of human cells. First, they showed that CR3014 escape variants all had the same small change in a part of the virus surface that interacts with human cells. CR3014 blocked this interaction in the parent SARS$\mathrm{CoV}$ strain but not in the escape variants. They then made a new monoclonal antibody-CR3022-that prevented both the parent SARSCoV stain and the CR3014 escape viruses from killing human cells. The two antibodies bound to neighboring parts of the virus surface, and both of them could bind at the same time. CR3022 also bound to surfaces of SARS-CoV strains to which CR3014 does not bind. And when they tried, the researchers could not generate any viral escape variants to which CR3022 was unable to bind. Finally, the effect of the two antibodies together on inhibition of SARS-CoV killing of human cells was more than the sum of their individual effects.

What Do These Findings Mean? A combination of two (or more) human monoclonal antibodies that recognize different parts of the SARS-CoV surface that interacts with human cells might be a good way to immunize people passively against SARS-CoV. It might minimize the possibility of escape variants arising, broaden the range of virus strains against which protection is provided, and reduce the amount of antibody needed for effective protection. Before the approach is tried in people, it will have to be tested in animals - results from experiments done on human cells in dishes are not always replicated in whole animals or people. If the approach passes further tests, the hope is that passive immunization of people with SARS and their close contacts might reduce disease severity in infected people and reduce viral spread as effectively as dramatic quarantine measures

Additional Information. Please access these websites via the online version of this summary at http://dx.doi.org/10.1371/journal.pmed. 0030237.

- Medline Plus pages on SARS

- US Centers for Disease Control and Prevention information on SARS

- US National Institute of Allergy and Infectious Diseases factsheet about research on SARS

- Wikipedia page on SARS and monoclonal antibodies (note: Wikipedia is a free online encyclopedia that anyone can edit) 